\title{
Perioperative lung protective ventilation in obese patients
}

Ana Fernandez-Bustamante ${ }^{1,2^{*}}$, Soshi Hashimoto ${ }^{3}$, Ary Serpa Neto ${ }^{4,5}$, Pierre Moine ${ }^{1}$, Marcos F Vidal Melo ${ }^{3}$ and John E Repine $e^{2,6}$

\begin{abstract}
The perioperative use and relevance of protective ventilation in surgical patients is being increasingly recognized. Obesity poses particular challenges to adequate mechanical ventilation in addition to surgical constraints, primarily by restricted lung mechanics due to excessive adiposity, frequent respiratory comorbidities (i.e. sleep apnea, asthma), and concerns of postoperative respiratory depression and other pulmonary complications. The number of surgical patients with obesity is increasing, and facing these challenges is common in the operating rooms and critical care units worldwide. In this review we summarize the existing literature which supports the following recommendations for the perioperative ventilation in obese patients: (1) the use of protective ventilation with low tidal volumes (approximately $8 \mathrm{~mL} / \mathrm{kg}$, calculated based on predicted -not actual- body weight) to avoid volutrauma; (2) a focus on lung recruitment by utilizing PEEP $\left(8-15 \mathrm{cmH}_{2} \mathrm{O}\right)$ in addition to recruitment maneuvers during the intraoperative period, as well as incentivized deep breathing and noninvasive ventilation early in the postoperative period, to avoid atelectasis, hypoxemia and atelectrauma; and (3) a judicious oxygen use (ideally less than 0.8) to avoid hypoxemia but also possible reabsorption atelectasis. Obesity poses an additional challenge for achieving adequate protective ventilation during one-lung ventilation, but different lung isolation techniques have been adequately performed in obese patients by experienced providers. Postoperative efforts should be directed to avoid hypoventilation, atelectasis and hypoxemia. Further studies are needed to better define optimum protective ventilation strategies and analyze their impact on the perioperative outcomes of surgical patients with obesity.
\end{abstract}

Keywords: Lung protective ventilation, Obese surgical patients, Mechanical ventilation, Perioperative ventilation, Obesity

\section{Introduction}

Proper ventilatory settings have a proven impact on clinical outcomes in Intensive Care Unit (ICU) patients with or without risk for the Acute Respiratory Distress Syndrome (ARDS) [1,2]. While lung protective ventilation with low tidal volumes $\left(\mathrm{V}_{\mathrm{T}}\right)$ and the use of positive end-expiratory pressure (PEEP) are now considered routine for ICU patients, the implementation of protective ventilation strategies in the operating room is not widespread [3-5]. These practices may reflect the shortage of convincing prospective trials showing a significant negative impact of non-protective ventilation of short duration on clinical

\footnotetext{
* Correspondence: Ana.Fernandez-Bustamante@ucdenver.edu

'Department of Anesthesiology, University of Colorado SOM, Aurora, CO,

USA

${ }^{2}$ Department of Anesthesiology and Webb-Waring Center, University of

Colorado SOM, Aurora, CO, USA

Full list of author information is available at the end of the article
}

outcomes of patients with healthy lungs. However, the relevance of optimal mechanical ventilation for surgical patients during general anesthesia is being increasingly recognized. Recent studies [6-8] and meta-analyses $[9,10]$ suggest that intraoperative ventilatory practices may contribute not only to ARDS but also to the development of other postoperative pulmonary complications. Although postoperative ARDS is rare in patients at low risk, postoperative pulmonary complications including atelectasis, pneumonia, or respiratory failure, can occur in up to $40 \%$ in high-risk patients [11] and are associated to worse surgical outcomes [12].

Adequate ventilation of the surgical patient with obesity is particularly challenging because of the unique loads to lung mechanics posed by excessive restrictive adiposity, the common presence of additional respiratory morbidities such as asthma or sleep apnea, and/or concerns regarding 
postoperative respiratory depression related to the altered pharmacokinetics with increased adiposity. The real-topredicted body weight disparity in obese patients and the unique use of height, instead of weight, in formulas used for tidal volume calculation based on predicted body weight [1] undoubtedly contribute to obesity being a recurrent risk factor for receiving inappropriately large tidal volumes during mechanical ventilation $[3,5,13]$.

Ventilating obese patients is becoming a frequent challenge since the prevalence of obesity is steadily increasing and reaching epidemic proportions worldwide $[14,15]$. Fitucane et al. [15] found a worldwide average increase in age-standardized Body Mass Index (BMI, defined as weight $(\mathrm{kg}) /$ height $\left.(\mathrm{m})^{2}\right)$ of $0.4-0.5 \mathrm{~kg} / \mathrm{m}^{2}$ per decade from 1980 until 2008, with the greatest BMI in the United States for both males and females. An estimated 9.8$13.8 \% \%$ of the worldwide population were affected by obesity (BMI $\geq 30)$ in 2008 , translating into approximately 500 million adults (older than 20 years). The obesity prevalence is greater than $20 \%$ in adults from many industrialized countries, surpassing the $30 \%$ in the United States $[14,15]$. Although it is unproven that obesity per se increases the risk of postoperative pulmonary complications $[16,17]$, reports of postoperative hypoxemia, ICU admission and other resources use, and hospital length of stay, are often greater, especially in the presence of severe obesity and/or sleep apnea [18-20].

In this review, we will summarize and focus on the current-state of knowledge regarding the use of protective ventilation for intra- and peri-operative purposes for obese patients.

\section{Background of perioperative protective ventilation}

Mechanical injury to the blood-gas barrier is the hallmark of ventilator-induced lung injury (VILI). The main determinants of VILI depend on the nature, duration, and intensity of exposure: in short, the mechanical "hit" to the lung $[21,22]$. Initial studies in rodent models showed that mechanical ventilation with larger tidal volumes $\left(\mathrm{V}_{\mathrm{T}}\right)$ causes structural pulmonary damage (volutrauma) that mimics ARDS [21-26]. This injury can begin within minutes of ventilation $[22,26]$. Larger $V_{T}$ with alveolar overdistention [21-24] and cyclical opening and collapse (atelectrauma) [27] of alveoli can trigger and amplify a local inflammatory reaction of the lung (biotrauma) [28-30]. These events can potentially lead to diffuse alveolar damage characterized by pulmonary edema, recruitment and activation of inflammatory cells, local production of inflammatory mediators, and leakage of mediators into the systemic circulation [21,22,28,31-36]. Preexisting or concomitant lung alterations (i.e. underlying lung disease, systemic inflammation and/or pulmonary edema) likely make the diseased lung parenchyma much more susceptible to mechanical injury [22,26,37]. The clinical translation of these findings in animal models of VILI and ARDS has been confirmed. In patients with ARDS, a multicenter prospective ARDS Network Trial and other studies repeatedly found that, compared with conventional ventilation (with $\mathrm{V}_{\mathrm{T}}>10 \mathrm{~mL} / \mathrm{kg}$ predicted body weight, $\mathrm{PBW}$ ), protective ventilation with lower $\mathrm{V}_{\mathrm{T}}(6 \mathrm{~mL} / \mathrm{kgPBW})$ [1] decreases neutrophil alveolar infiltration and the levels of proinflammatory mediators in the bronchoalveolar lavage and systemically, increases the number of ventilator-free days and reduces the in-hospital mortality $[1,29,30]$. For this reason, in Intensive Care Unit (ICU) patients, mechanical ventilation with low $V_{T}$ is the standard practice for preventing and managing VILI and acute respiratory distress syndrome (ARDS) [2,23].

No clear guidelines exist for setting $\mathrm{V}_{\mathrm{T}}$ and optimal ventilator management in patients without ARDS. Despite controversial findings [38], several animal and human studies suggest an association between higher $V_{T}$ and early increased inflammation and ARDS in subjects without preexisting lung disease [9,36,39-48]. Recent findings reveal improved clinical outcomes (lower incidence of ARDS, mortality) when low $\mathrm{V}_{\mathrm{T}}$ ventilation is used in mechanically ventilated patients without ARDS [6,9,49]. Moreover, donor lungs from patients after brain death were better protected when receiving a low $\mathrm{V}_{\mathrm{T}}$ strategy combined with alveolar recruitment maneuvers, an approach that made the lungs more likely to meet the criteria for donation [50]. Lung transplant recipients included in the protective ventilation strategy group had a $6 \%$ better survival after 6 months [50]. Thus, lung protective ventilation strategies appear to have preventative value not only in patients with healthy lungs but also in individuals receiving transplanted lungs [51].

Postoperative ARDS and other postoperative pulmonary complications, including atelectasis, pneumonia and respiratory failure, adversely impact clinical outcomes and increase hospital length of stay and medical costs $[52,53]$. Preventing these complications is increasingly a measure of the quality of hospital care [12]. During surgery, anesthesiologists use mechanical ventilation in patients with healthy lungs, a variety of respiratory conditions, and even in patients who are developing or will develop several other potential insults to the lung, including sepsis, trauma, lung ischemia-reperfusion, cardiac surgery, or blood transfusion $[9,13,36,39-47,49]$. Many of these nonventilation insults are not preventable or avoidable, but contribute to increase the risk of postoperative ARDS development. The use of lower $V_{T}$ ventilation is one of the few preventative measures that can be used to preserve lung health. Unfortunately, the intraoperative use of large $\mathrm{V}_{\mathrm{T}}$ (greater than $10 \mathrm{~mL} / \mathrm{kgPBW}$ ) and no PEEP is not a rare finding, particularly in patients with obesity or short height [3-5]. The awareness and relevance of this likely unintentional practice has increased during the last few 
years. In particular, the recent IMPROVE trial [6], a multicenter, double-blind clinical trial, showed improved pulmonary outcomes (pneumonia, acute respiratory failure, atelectasis) and shortened hospital stays in patients ventilated for elective major abdominal surgery with a protective ventilation management approach $\left(\mathrm{V}_{\mathrm{T}} 6-8 \mathrm{~mL} / \mathrm{kgPBW}\right.$, PEEP 6-8 $\mathrm{cmH}_{2} \mathrm{O}$ and protocolized recruitment maneuvers) compared to a non-protective strategy $\left(\mathrm{V}_{\mathrm{T}} 10\right.$ $12 \mathrm{~mL} / \mathrm{kgPBW}$, PEEP $0 \mathrm{cmH}_{2} \mathrm{O}$, no recruitment maneuvers) [6]. Results from the IMPROVE study turned the focus into not only avoiding volutrauma (by using low $\mathrm{V}_{\mathrm{T}}$ ) but also minimizing atelectrauma with adequate recruitment maneuvers and PEEP.

Another multicenter controlled study, the PROVHILO trial [8], randomized patients at risk for pulmonary complications after open abdominal surgery to receive intraoperative protective ventilation $\left(\mathrm{V}_{\mathrm{T}} 8 \mathrm{~mL} / \mathrm{kgPBW}\right)$ with either high PEEP (12 $\mathrm{cmH}_{2} \mathrm{O}$ and recruitment maneuvers) or low PEEP $\left(2 \mathrm{cmH}_{2} \mathrm{O}\right.$ and no recruitment maneuvers). No difference in a composite of varied pulmonary complications (including hypoxemia or ARDS but also pneumothorax or cardiogenic pulmonary edema) during the first 5 postoperative days was observed between the groups. Intraoperatively, the PROVHILO low PEEP group required more interventions for desaturation and the high PEEP group required more interventions for hypotension. Thus, the search for optimal intraoperative ventilation settings is still incomplete. Ongoing efforts include the PROBESE study (http://www.clinicaltrials.gov/ct2/show/ NCT02148692?term=probese\&rank=1), a multicenter controlled trial specifically focused on the intraoperative ventilation of surgical patients with obesity.

More prospective clinical studies are needed to define the perioperative ventilation strategies for $\mathrm{V}_{\mathrm{T}}$, PEEP and recruitment maneuvers that improve pulmonary outcomes, both in the general surgical and obese surgical populations.

\section{Perioperative pulmonary challenges related to obesity}

Obese patients often present with additional pulmonary comorbidities, including airway hyper-reactivity, sleep apnea (SA), obesity hypoventilation syndrome (OHS) and pulmonary hypertension. Obesity induced airway hyper-reactivity is gaining attention as a specific type of bronchial hyperreactivity that can be differentiated from other asthma etiologies in terms of age of onset and response to standard therapy or weight loss [54-56]. Sleep apnea is distinguished by multiple interruptions of ventilation during the sleep and their consequences (intermittent nocturnal hypoxemia and daytime tiredness). In obese patients, sleep apnea is usually from upper airway obstruction as a result of excessive soft pharyngeal tissue, rather than from a central deregulation of the respiratory drive center [57]. The fact that the time-consuming and expensive gold-standard diagnostic polysomnography is not done routinely probably contributes to a high incidence of undiagnosed sleep apnea in surgical patients [58-60]. Sleep apnea increases the risk of postoperative hypoxemia, other respiratory complications and ICU admission [18,19], and especially if untreated, also may contribute to hypertension and other cardiovascular risks $[61,62]$. Obesity hypoventilation syndrome (OHS) is the combination of daytime hypercapnia and sleep-disordered breathing in an obese patient, and is notably a condition that is not related to any other pulmonary or neuromuscular pathology $[63,64]$. OHS is frequently undiagnosed (and untreated) [65] until an acute-on-chronic respiratory failure occurs, frequently during the perioperative period $[64,66]$. Pulmonary hypertension often arises from the chronicity of SA or OHS, and may lead to right ventricular failure.

Aside from the previously mentioned comorbidities that can complicate the perioperative oxygenation and ventilation of surgical patients, obesity itself poses specific challenges to intraoperative airway management. Obesity and sleep apnea are frequently mentioned risk factors for difficult mask ventilation and/or tracheal intubation $[67,68]$. In addition to the technical challenges, the reduced functional residual capacity (FRC), increased ventilation-perfusion mismatch and respiratory comorbidities make anesthetic induction and airway management a high-risk period for hypoxemic events and other respiratory complications.

The implications of obesity on pulmonary physiology are well known [69] (Table 1). Obesity increases chest wall elastic resistance and decreases the respiratory system compliance [70,71]. Reduced respiratory system compliance is partially related to the extra adipose tissue in the chest wall but also the increased pulmonary blood volume. Most lung capacities are decreased, primarily the FRC and the expiratory reserve volume (ERV) [72-74]. The lower FRC, especially in the supine position, often leads to lung volumes lower than the closing capacity, causing ventilation-perfusion mismatch and hypoxemia. Ventilation then takes place in the less compliant portion of the pressure-volume curve, increasing the effort needed to overcome this decreased respiratory elasticity. The autoPEEP secondary to airway closure during expiration contributes to the increased work of breathing (WOB) due to the additional ventilatory effort required by the diaphragm and other inspiratory muscles during the next inspiration $[75,76]$. Other factors potentially involved in the increased WOB apart from the altered respiratory mechanics are an upper airway mechanical obstruction, neuromuscular weakness, impaired gas exchange, and dampened ventilatory drive [77]. To reduce WOB, obese subjects usually adopt a breathing pattern with reduced tidal volumes and higher respiratory rates [78]. Additionally, due to the metabolism of the excess adipose tissue, obese patients have 
Table 1 Changes of respiratory mechanics and functions in obese patients

\begin{tabular}{|c|c|}
\hline Physiological changes & Challenges for respiratory management \\
\hline Excessive oro-pharyngeal adiposity & Upper airway obstruction \\
\hline Increased risk of pharyngeal collapse during sleep & Frequent sleep apnea/obesity hypoventilation syndrome \\
\hline Decreased compliance (chest wall > lung) & Decreased compliance during mechanical ventilation \\
\hline \multicolumn{2}{|l|}{ Increased airway resistance } \\
\hline \multicolumn{2}{|l|}{ Increased work of breathing } \\
\hline Increase in resting $\mathrm{VO}_{2}$ & Frequent hypoxemic events \\
\hline Decrease in FRC and EELV & Atelectasis \\
\hline FRC $<$ closing capacity & Rapid oxygen desaturation \\
\hline \multicolumn{2}{|l|}{ Small airway closure } \\
\hline \multicolumn{2}{|l|}{ Alveolar collapse } \\
\hline \multicolumn{2}{|l|}{ Ventilation-perfusion $(\mathrm{V} / \mathrm{Q})$ mismatch } \\
\hline Increased PA-aO2, Decreased PaO2 & \\
\hline
\end{tabular}

increased oxygen consumption and carbon dioxide production [70,71]. All these changes are more prominent when patients are in the supine position because increased intraabdominal pressure restricts diaphragmatic movement and lung expansion.

Postoperatively, the major respiratory concerns of obese patients are related to their increased risk of hypoxemia and respiratory failure related to opioid-enhanced central respiratory depression, upper airway obstruction, and hypoventilation atelectasis. Particular focus must be directed to implementing an adequate opioid-sparing analgesia plan, encouraging deep breathing techniques, providing noninvasive positive pressure ventilation to minimize atelectasis and assuring adequate ventilation. Recent reviews offer further details on the postoperative care of surgical patients $[64,68,79]$.

\section{Practices and recommendations for perioperative mechanical ventilation of the surgical patient with obesity}

Several studies have been conducted about determining the best ventilatory strategies for obese patients under general anesthesia (Table 2). Pressure-controlled ventilation $(\mathrm{PCV})$ is often the preferred ventilatory mode in obese patients, because of the more homogeneous distribution of delivered gas mixture and the increased possibility of avoiding alveolar distension and improving ventilationperfusion mismatch when compared with volume-controlled ventilation (VCV). Some studies [80,81] demonstrate improved oxygenation with intraoperative PCV, compared to $\mathrm{VCV}$ in obese patients. However, no ventilatory mode significantly improves optimum delivered $\mathrm{V}_{\mathrm{T}}$ or mean airway pressures [82-84]. There is also no information suggesting superior clinical outcomes with intraoperative PCV or VCV use in obese patients [82] and they should be, therefore, selected under adequate understanding of their different operation and characteristics to achieve the goals of lung protective ventilation and avoid both volu/barotrauma and hypoventilation. Another ventilatory mode, Pressure-Controlled Ventilation Volume-Guaranteed (PCV-VG) has been added to modern anesthesia machines within the last years. PCV-VG is a time-cycled, pressureregulated mode with a variable inspiratory flow to achieve a preset $\mathrm{V}_{\mathrm{T}}$. PCV-VG poses some theoretical advantages in the obese patient by assuring a minimum $V_{T}$ with lower peak inspiratory pressures (PIP). However, the literature regarding its use in obese individuals is presently scarce. A very small crossover study [85] in 20 severely obese $\left(\mathrm{BMI} \geq 40 \mathrm{~kg} / \mathrm{m}^{2}\right.$ ) adolescents or young adults receiving 20 minutes of ventilation with VCV, PVC or PCVVG during laparoscopic bariatric surgery observed a lower PIP with PCV and PCV-VG modes, compared to VCV, but no differences in oxygenation or ventilation. Future studies are needed to evaluate the use of PCV-VG for ventilating the surgical patient with obesity.

Tidal volume settings require special attention in obese patients. Obese patients are more often exposed to greater $\mathrm{V}_{\mathrm{T}}[3,5,13,86]$, an observation that likely reflects the practice of basing $\mathrm{V}_{\mathrm{T}}$ computations on actual instead of predicted body weight. It is important to highlight, particularly in obese patients, that the desired $\mathrm{V}_{\mathrm{T}}$ should be calculated based on the predicted body weight and not on the actual body weight because the increased thoracic appearance is due to excessive adipose tissue but not a greater intrathoracic (lung) volume. Despite the not-rare findings of large $\mathrm{V}_{\mathrm{T}}$ used in obese patients, the clinical implications are unclear. A secondary analysis of the ARDS Network trial by O'Brien et al. [86] revealed that $58.6 \%$ of the studied population was overweight or obese. These obese patients presented greater initial (before study protocol) $V_{\mathrm{T}}$ and 
Table 2 Clinical trials comparing PCV with VCV in obese patients

\begin{tabular}{|c|c|c|c|c|c|c|c|c|c|c|c|c|c|c|}
\hline \multirow[t]{2}{*}{ Year } & \multirow[t]{2}{*}{ Author } & \multirow[t]{2}{*}{ Intervention } & \multirow[t]{2}{*}{$\mathrm{n}$} & \multirow[t]{2}{*}{ Weight (kg) } & \multirow[t]{2}{*}{ BMI } & \multirow[t]{2}{*}{$\mathrm{V}_{\mathrm{T}}(\mathrm{mL})$} & \multirow[t]{2}{*}{ Height (m) } & \multirow[t]{2}{*}{$\mathrm{V}_{\mathrm{T}} / \mathrm{PBW}$} & \multirow{2}{*}{$\begin{array}{l}\text { RR } \\
\text { (breath/min) }\end{array}$} & \multirow{2}{*}{$\begin{array}{l}\text { PIP } \\
\left(\mathrm{cmH}_{2} \mathrm{O}\right)\end{array}$} & \multirow{2}{*}{$\begin{array}{l}\mathrm{Ppl} \\
\left(\mathrm{cmH}_{2} \mathrm{O}\right)\end{array}$} & \multirow{2}{*}{$\begin{array}{l}\text { PEEP } \\
\left(\mathrm{cmH}_{2} \mathrm{O}\right)\end{array}$} & \multicolumn{2}{|l|}{ Outcome } \\
\hline & & & & & & & & & & & & & Oxygenation & Ventilation \\
\hline \multirow[t]{2}{*}{2008} & Cadi [80] & PCV & 18 & $121(21)$ & $44(5)$ & $613(91)$ & & $11(1.4)$ & $18(0.5)$ & $26(4)$ & $26(4)$ & 5 & $\uparrow$ & $\uparrow$ \\
\hline & & VCV & 18 & $119(17)$ & $45(5)$ & $573(81)$ & & $10.2(1.2)$ & $18(1.0)$ & $33(4)$ & $27(3)$ & 5 & & \\
\hline \multirow[t]{2}{*}{2008} & De Baerdemaeker [84] & PCV & 12 & $111.7(19.2)$ & $38.6(3.6)$ & $612(170)$ & $1.70(0.12)$ & NA & $11.8(1.8)$ & $25.8(1.6)$ & $25.8(1.6)$ & 5 & $\rightarrow$ & $\downarrow$ \\
\hline & & VCV & 12 & $117.4(22.3)$ & $41.4(4.5)$ & $645(138)$ & $1.68(0.10)$ & NA & $11.7(1.2)$ & $28.9(4.2)$ & $25.1(3.7)$ & 5 & & \\
\hline \multirow[t]{2}{*}{2008} & Hans [83] & PCV & crossover & NA & crossover & $650(104)$ & & $10.0(1.9)$ & $12.2(0.5)$ & $21.5(4.8)$ & $21.5(4.8)$ & 0 & $\rightarrow$ & $\rightarrow$ \\
\hline & & VCV & 40 & NA & 41.7 (5.8) & $643(100)$ & & $9.9(1.8)$ & $12.2(0.5)$ & $26.8(5.2)$ & $20.9(4.6)$ & 0 & & \\
\hline
\end{tabular}

(BMI = Body Mass Index; PBW = Predicted Body Weight; PIP = Peak Inspiratory Pressure; Ppl = plateau airway pressure; RR = Respiratory rate; $\mathrm{V}_{\mathrm{T}}=$ Tidal volume; $\uparrow=$ increased; $\downarrow=$ decreased; $\rightarrow=$ unchanged). 
peak and plateau airway pressures. However, the outcomes associated with ARDS were not significantly different between obese and normal-weight patients [86]. Therefore, a greater awareness for appropriate selection of low $\mathrm{V}_{\mathrm{T}}$ in obese patients is highly recommended, but further investigations are needed to determine the ideal $\mathrm{V}_{\mathrm{T}}$ (and other ventilatory) settings for obese patients.

Achieving adequate ventilation with airway plateau pressures $\leq 30 \mathrm{cmH}_{2} \mathrm{O}$ [1] is often challenging in obese surgical patients due to the decreased respiratory system compliance along with surgical-related factors (i.e. pneumoperitoneum, surgical retractors or Trendelenburg position) that further compromise lung expansion. Lewandowski et al. [87] suggested that greater inflation pressures may be tolerated by obese patients, possibly because the extra intrathoracic adiposity may limit lung overdistention [21]. Esophageal pressures are increased in spontaneously breathing obese individuals compared to lean subjects $[74,88]$, which probably translates into reduced transpulmonary pressures. Ventilation guided by esophageal pressure has beneficial effects in oxygenation and compliance optimization in patients with ARDS [89], but this ventilation approach has not been attempted in obese surgical patients.

It is however well accepted that obese subjects are prone to develop atelectasis primarily in dependent lung areas, making recruitment maneuvers and application of PEEP a vital strategy to improve oxygenation and lung mechanics $[90,91]$ (Table 3). Many studies indicate that a recruitment maneuver (RM) and PEEP reduced atelectasis and improved oxygenation in obese patients during surgery. A recent meta-analysis by Aldenkortt et al. [82] concluded that adding recruitment maneuvers to PEEP in these obese patients improved oxygenation and lung compliance without increasing the risk of hypotension from decreased preload. This open lung concept also seems to be potentially important in preventing the development of ventilator-induced lung injury by stabilizing alveoli and keeping them open, especially for patients undergoing major surgery. Additionally, the application of PEEP may also efficiently offset airflow limitation in the supine position and eliminate auto-PEEP without raising plateau pressure [92]. Indeed, increase in lung inflation may improve lung ventilation not only in large but also in small length scale regions even in normal lungs [93]. This is consistent with the reduction of heterogeneous mechanical forces at the microscopic level, a potential cause of VILI [94]. A recent meta-analysis [95] suggested that an open lung approach with PEEP in surgical patients improves postoperative oxygenation and decreases postoperative atelectasis without any adverse events, although this needs further confirmation. In obese patients, the efficiency of recruitment maneuvers and PEEP on postoperative outcomes such as oxygenation and pulmonary function remains controversial. The study by Talab et al. [91] found that obese patients receiving recruitment maneuvers followed by PEEP of $10 \mathrm{cmH}_{2} \mathrm{O}$ had reduced lung atelectasis, improved intra- and post-operative oxygenation, shortened post-anesthesia care unit stay and fewer pulmonary complications than patients ventilated with lower PEEP levels. In contrast, Whalen et al. [96] observed that, although recruitment maneuvers followed by PEEP $12 \mathrm{cmH}_{2} \mathrm{O}$ effectively increased intraoperative oxygenation, this effect disappeared $30 \mathrm{~min}$ after tracheal extubation. Thus, the postoperative effect and impact on clinical outcomes of these intraoperative lung recruitment efforts needs to be further studied. Ongoing studies, such as the multicenter PROBESE study mentioned earlier, may offer some answers to this question.

During the early postoperative period and spontaneous breathing, obese surgical patients experience more severe alveolar collapse and impairment of gas exchange than normal-weight patients. Therefore, a head-up or sitting position, encouragement of deep breathing exercises, mobilization and incentive spirometry and continuous or bilevel positive airway pressure (CPAP/BiPAP) may prevent atelectasis and hypoxemia and reduce postoperative complications in obese patients.

Lastly, some controversy exists regarding the ideal inspired oxygen concentration. Obese patients often receive high oxygen concentrations because of the increased risk of the aforementioned perioperative hypoxemic events. Oxygen is obviously needed for adequate oxygenation and may have beneficial effects for postoperative nausea and surgical site infection [97]. For unknown reasons, administering high oxygen concentrations is associated with worse outcomes after myocardial infarction, cardiac arrest, stroke and in critically ill adults. Because high oxygen concentrations may enhance absorption atelectasis and worsen postoperative outcomes, some authors recommend maintaining inspired oxygen concentrations lower than 0.8 in obese patients [68,98]. However, in a recent meta-analysis Hovaguimian et al. [97] failed to find solid evidence to support this recommendation. Therefore, judicious use of oxygen to assure adequate oxygenation in obese surgical patients is prudent until more scientific knowledge is available.

A summary of the previously described practical recommendations is included in Figure 1.

\section{One lung ventilation (OLV) in obese patients}

Literature on the effect of OLV for the obese patient is scarce. However, the current knowledge is included herein because of the increasing number of obese patients requiring thoracic surgery.

Lung isolation for OLV is often achieved for thoracic surgery with either a double lumen tracheal tube or a single lumen tracheal tube followed by a bronchial blocker. 
Table 3 Clinical trials to assess the efficacy of open lung strategy

\begin{tabular}{|c|c|c|c|c|c|c|c|c|c|c|c|c|c|c|}
\hline \multirow[t]{3}{*}{ Year } & \multirow[t]{3}{*}{ Author } & \multirow[t]{3}{*}{ Intervention } & \multirow{2}{*}{\multicolumn{2}{|c|}{$\begin{array}{l}\text { Recruitment maneuver } \\
\text { Continuous pressure }\end{array}$}} & \multirow[t]{3}{*}{$\mathrm{n}$} & \multirow[t]{3}{*}{ Weight (kg) } & \multirow[t]{3}{*}{ BMI } & \multirow{3}{*}{$\begin{array}{l}\mathrm{V}_{\mathrm{T}} / \mathrm{BW} \\
(\mathrm{mL} / \mathrm{kg})\end{array}$} & \multirow{3}{*}{$\begin{array}{l}\text { RR } \\
\text { (breath/min) }\end{array}$} & \multirow{3}{*}{$\begin{array}{l}\text { PEEP } \\
(\mathrm{cmH} 2 \mathrm{O})\end{array}$} & \multicolumn{4}{|c|}{ Outcome variables } \\
\hline & & & & & & & & & & & \multirow{2}{*}{ Oxygenation } & \multirow[t]{2}{*}{ Atelectasis } & \multirow{2}{*}{$\begin{array}{l}\text { PACU or } \\
\text { hospital } \\
\text { stay }\end{array}$} & \multirow{2}{*}{$\begin{array}{l}\text { Postoperative } \\
\text { pulmonary } \\
\text { complications }\end{array}$} \\
\hline & & & Paw (cmH2O) & Time (s) & & & & & & & & & & \\
\hline \multirow[t]{2}{*}{2007} & Chalhoub [128] & PEEP + RM40 & 40 & 15 & 26 & $130(18)$ & $44.4(3.7)$ & 10 & $12(4)$ & 8 & $\uparrow$ & NA & NA & NA \\
\hline & & PEEP & & & 26 & $131(23)$ & $45.5(5.3)$ & 10 & $13(3)$ & 8 & & & & \\
\hline \multirow[t]{4}{*}{2009} & de Souza [129] & PEEP + RM30 & 30 & 120 & 16 & $123.7(20.6)$ & $46.3(5.0)$ & $8-10$ & $12-14 / \mathrm{min}$ & 5 & $\nearrow$ & NA & NA & NA \\
\hline & & PEEP + RM10/15/20 & Stepwise metho & $*^{* 1}$ & 17 & $136.4(26.6)$ & $50.5(7.2)$ & $8-10$ & $12-14 / \mathrm{min}$ & 5 & & NA & NA & NA \\
\hline & & PEEP & & & 14 & $129.9(22.4)$ & $49.2(6.3)$ & $8-10$ & $12-14 / \mathrm{min}$ & 5 & & $\nearrow$ & & \\
\hline & & & & & & & & & & & & $\uparrow$ & & \\
\hline \multirow[t]{3}{*}{2011} & Futier [130] & $P E E P+N P P V+R M$ & 40 & 40 & 22 & $128(17)$ & $45(5)$ & 8 & $20(20-21)$ & 10 & $\nearrow$ & (EELV) & NA & NA \\
\hline & & PEEP + NPPV & & & 22 & $128(20)$ & $46(2)$ & 8 & $20(20-20)$ & 10 & & (EELV) & NA & NA \\
\hline & & PEEP & & & 22 & $130(28)$ & $46(4)$ & 8 & $20(18-20)$ & 10 & & & & \\
\hline \multirow[t]{3}{*}{2009} & Reinius [131] & $\mathrm{RM}+\mathrm{PEEP}$ & 55 & 10 & 10 & $126(9)$ & $45(5)$ & 10 & $12 / \min$ & 10 & $\uparrow$ & $\downarrow$ & NA & NA \\
\hline & & $\mathrm{RM}+\mathrm{ZEEP}$ & 55 & 10 & 10 & $130(13)$ & $45(4)$ & 10 & $12 / \mathrm{min}$ & 0 & $\rightarrow$ & $\rightarrow$ & NA & NA \\
\hline & & PEEP & & & 10 & $120(14)$ & $44(3)$ & 10 & $12 / \mathrm{min}$ & 10 & & & & \\
\hline \multirow[t]{3}{*}{2009} & Talab [91] & $\mathrm{RM}+\mathrm{PEEP} 10$ & 40 & $7-8$ & 20 & NA & $44.5(7.0)$ & $8-10$ & NA & 10 & $\uparrow$ & $\downarrow$ & $\downarrow$ & $\downarrow$ \\
\hline & & $\mathrm{RM}+\mathrm{PEEP5}$ & 40 & $7-8$ & 19 & NA & $38.3(6.9)$ & $8-10$ & NA & 5 & $\rightarrow$ & $\rightarrow$ & $\rightarrow$ & $\rightarrow$ \\
\hline & & $\mathrm{RM}+\mathrm{ZEEP}$ & & & 19 & NA & $41.8(7.9)$ & $8-10$ & NA & 0 & & & & \\
\hline \multirow[t]{3}{*}{2006} & Whalen [96] & RM + PEEP12 & Stepwise metho & $* 2$ & 10 & NA & $48(6)$ & $12.7(1.5)$ & $17(4)$ & 12 & $\uparrow$ & NA & $\rightarrow$ & $\rightarrow$ \\
\hline & & PEEP4 & & & 10 & NA & $53(11)$ & $11.8(2.6)$ & $17(4)$ & 4 & & & & \\
\hline & & & & & & & & $\begin{array}{l}\text { LBW: lean } \\
\text { body weight }\end{array}$ & & & & & & \\
\hline
\end{tabular}

*1: Increase in PEEP from 5 to $10-15-20 \mathrm{cmH} 2 \mathrm{O}$ for 2 min each.

*2: Increasing in PEEP from 4 to 10 (over 3 breaths), 15 (3 breaths), and 20 (10 breaths). 


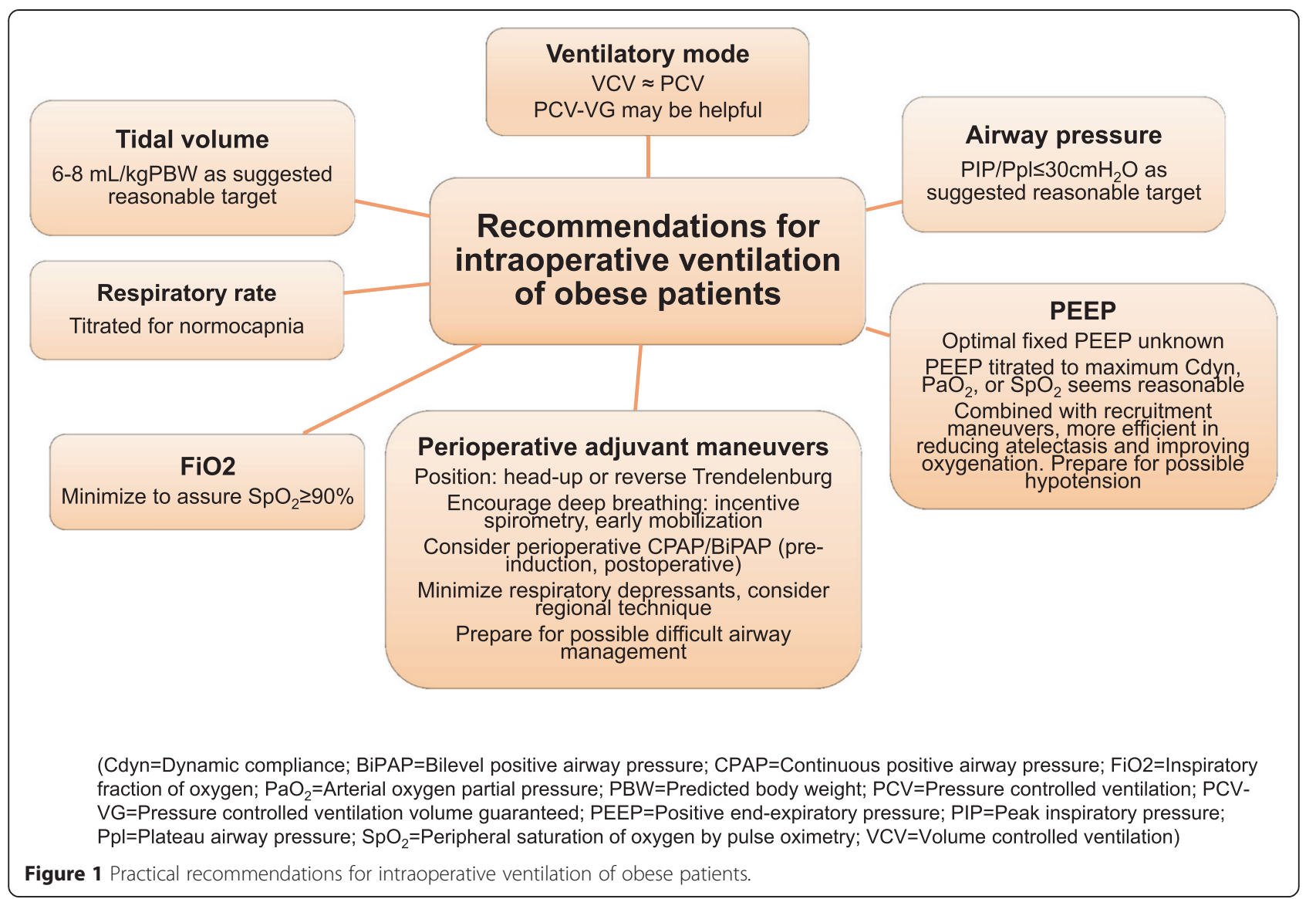

In a recent study of obese thoracic surgery patients, Campos et al. found both techniques produced similar results in terms of the incidence of failed first attempts, malposition after achieving lateral decubitus position, time to lung deflation or surgical exposure [99]. The fact that only providers experienced with both techniques performed this study should be considered.

Although clinical trials testing the best ventilator settings of obese patients during thoracic surgery are limited, the essential principles of ventilator management in obese patients seem not to be different from the choices used in non-obese patients. In the past, $\mathrm{V}_{\mathrm{T}}$ of $10-12 \mathrm{~mL} / \mathrm{kgPBW}$ during one-lung ventilation (OLV) was recommended to maintain gas exchange and normalize arterial oxygen and carbon dioxide values. This concept is based on the previous study by Katz [100], which showed that large $\mathrm{V}_{\mathrm{T}}$ produced the highest arterial oxygen tension during OLV. In fact, perioperative hypoxemia during OLV is not uncommon, which results from an intrapulmonary shunt related to collapse of the non-dependent lung and increased atelectatic areas in the dependent lung. Therefore, the primary aim during OLV is to provide adequate oxygenation and $\mathrm{CO}_{2}$ elimination, while the potential harmful effects of ventilatory strategy were initially disregarded. On the other hand, post-pneumonectomy pulmonary edema (PPPE) and ARDS are the most serious pulmonary complications after lung resection. In a retrospective review, Jeon et al. [101] observed a 12\% incidence of postpneumonectomy ARDS within the first postoperative week in series that evaluated patients with primary lung cancer. The use of large $\mathrm{V}_{\mathrm{T}}$ and high airway pressures during OLV were associated with an increased risk of post-pneumonectomy ARDS. There is a growing body of evidence that the use of low $V_{T}$ provides better outcomes after thoracic surgery. Several studies, not specific to obese surgical patients, currently recommend the use of a lung protective strategy with $\mathrm{V}_{\mathrm{T}}$ of $4-6 \mathrm{~mL} / \mathrm{kgPBW}$ during OLV [102-104]. Additionally, the use of a low tidal volume during OLV may be associated with less lung water content [105].

Several studies [106-108] indicate that alveolar recruitment strategies during OLV are associated with better oxygenation and decreases in dead-space variables in non-obese patients. On the other hand, excessive airway pressures in the ventilated lung during OLV can also increase pulmonary vascular resistance and shift blood flow to the non-dependent lung. Michelet et al. [109] found that administering 5 and $10 \mathrm{cmH}_{2} \mathrm{O}$ PEEP was associated with improved oxygenation and continuous lung volume recruitment while giving $15 \mathrm{cmH}_{2} \mathrm{O}$ PEEP 
caused overdistention and increased shunt compared with the other PEEP levels. Thus, although the use of PEEP is crucial to treat and prevent atelectasis and hypoxemia, it must be used with careful attention to the possibility of causing lung overdistention, possibly producing or contributing to ventilator-induced lung injury. In particular, the probability of coexistent auto-PEEP in patients with severe chronic obstructive pulmonary disease (COPD) presenting for lung resection needs to be considered. The best level of PEEP during OLV remains unclear but there is wide variation in individual pulmonary responses to the application of PEEP $[110,111]$. In a recent study by Ferrando et al. [112], applying individualized PEEP in a PEEP Decrement Trial resulted in better oxygenation and lung mechanics after an alveolar recruitment maneuver than administering a standardized $5 \mathrm{cmH}_{2} \mathrm{O}$ of PEEP. Obese patients tend to suffer from alveolar collapse due to their decreased chest wall compliance. Therefore, in obese patients, the setting of optimal PEEP level to keep the lung open may be crucial especially because an inadequate PEEP level cannot prevent alveolar re-collapse after an alveolar recruitment maneuver, and the latter would be also expected to occur in thoracic surgery. When performing recruitment maneuvers, attention should be paid to their potential adverse effects including temporary desaturation, decreased preload, hypotension, arrhythmias, and barotrauma.

\section{Postoperative ventilation in obese patients in the ICU setting}

Most likely, as a consequence of the previously mentioned effects of obesity on lung physiology, frequently associated respiratory comorbidities and increased risk of atelectasis, obese surgical patients have a greater risk of respiratory failure and other postoperative pulmonary complications $[73,113]$. Several general care recommendations in the postoperative care of obese surgical patients have been proposed to decrease the risk of atelectasis [68]. Head-up sitting position, encouragement of deep breathing and the use of continuous positive airway pressure (CPAP) may improve postoperative lung mechanics and reduce postoperative complications in patients undergoing surgery [68,114]. Postoperative admission of obese surgical patients to the ICU or intermediate care units is not unusual for a more intense ventilatory monitoring.

When postoperative ventilation is needed in obese surgical patients, ventilatory practice in the ICU tends to follow recommended protective ventilation strategies, albeit not completely $[13,115]$ but more tightly than in the operating room [3,116]. However, Gajic et al. [49] reported that $24 \%$ of ICU patients with normal lungs ventilated for 2 days or longer develop ARDS [49]. In this study, the main risk factors for ARDS were large tidal volumes (OR 1.3 for each $\mathrm{mL} / \mathrm{kg}$ above $6 \mathrm{~mL} / \mathrm{kgPBW}$ ), blood transfusion, and restrictive lung disease [49]. Nonetheless, the impact that obesity poses on the risk of ARDS is still controversial. Although some authors [86,117,118] observed a similar or increased incidence of ARDS in severely obese patients, the clinical outcomes (i.e. mortality, hospital length of stay) of obese patients were similar to those in non-obese patients. Furthermore, other studies [119-121] found a decreased incidence and/or mortality from ARDS in obese patients, and decreased plasma concentrations of inflammatory mediators (IL-6, IL-8) during ARDS [122] in obese patients compared to normal-weight patients. It seems clear that obese patients, once they present with respiratory failure in the ICU, usually require longer durations of mechanical ventilation [123,124]. Therefore, the effect of different degrees of obesity on incidence and outcomes of ARDS and a wide array of cardiovascular and metabolic comorbidities is still not well explained. Overweight and mildly obese and otherwisehealthy patients may actually not be at increased risk of ARDS as initially expected [86,119-122,125], phenomenon that has been termed the Obesity ARDS Paradox. [126,127]. Further confirmation of this intriguing paradox and its underlying mechanisms are needed, but it might hold new insights into the pathophysiology, diagnosis, treatment and prevention of ARDS.

\section{Conclusions}

The increasing number of obese patients requiring surgery demands a better understanding of the particular challenges that obesity poses on mechanical ventilation. Obese patients present specific lung physiology and mechanics characteristics, frequent respiratory comorbidities and increased risk of postoperative pulmonary complications. Intraoperatively, lung protective ventilation with low tidal volumes, recruitment maneuvers with greater PEEP levels and the judicious use of oxygen concentrations are recommended. Focused postoperative care seeking to minimize atelectasis formation is critical. Further research is needed to identify the ideal perioperative respiratory care needed to enhance the outcomes and minimize postoperative pulmonary complications of obese surgical patients.

\footnotetext{
Abbreviations

ARDS: Acute respiratory distress syndrome; BiPAP: Bilevel positive airway pressure; BMI: Body mass index; Cdyn: Dynamic compliance; CPAP: continuous positive airway pressure; EELV: End-expiratory lung volume; ERV: Expiratory reserve volume; $\mathrm{FiO}_{2}$ : Inspiratory fraction of oxygen; FRC: Functional residual capacity; ICU: Intensive care unit; OHS: Obesity hypoventilation syndrome; OLV: One lung ventilation; PaO2: Arterial partial pressure of oxygen; PA-aO2: Alveolar to arterial partial pressure of oxygen; Paw: Airway pressure; PBW: Predicted body weight; PCV: Pressure-controlled ventilation; PCV-VG: Pressure-controlled ventilation volume-guaranteed; PEEP: Positive end-expiratory pressure; PIP: Peak inspiratory pressures; Ppl: Plateau airway pressure; RM: Recruitment maneuver; SA: Sleep apnea; $\mathrm{SpO}_{2}$ : Peripheral saturation of oxygen by pulse oximetry; VCV: Volume-controlled ventilation; VILI: Ventilator-induced lung injury; $\mathrm{VO}_{2}$ : Oxygen consumption; $\mathrm{V} / \mathrm{Q}$ : Ventilation/ perfusion; $V_{T}$ : Tidal volume; WOB: Work of breathing.
} 


\section{Competing interests}

The authors declare that they have no competing interests.

\section{Authors' contributions}

AFB, MFVM and JER conceived the review and drafted the manuscript. SH, ASN, PM contributed to the manuscript draft and tables. All authors read and approved the final manuscript.

\section{Author details}

${ }^{1}$ Department of Anesthesiology, University of Colorado SOM, Aurora, CO, USA. ${ }^{2}$ Department of Anesthesiology and Webb-Waring Center, University of Colorado SOM, Aurora, CO, USA. ${ }^{3}$ Department of Anesthesia, Critical Care and Pain Medicine, Massachusetts General Hospital, Boston, MA, USA. ${ }^{4}$ Department of Critical Care Medicine, Hospital Israelita Albert Einstein, São Paulo, Brazil. ${ }^{5}$ Department of Intensive Care, Academic Medical Center, University of Amsterdam, Amsterdam, The Netherlands. ${ }^{6}$ Department of Medicine, University of Colorado SOM, Aurora, CO, USA.

Received: 15 September 2014 Accepted: 2 April 2015 Published online: 06 May 2015

\section{References}

1. ARDSNet. Ventilation with lower tidal volumes as compared with traditional tidal volumes for acute lung injury and the acute respiratory distress syndrome. The acute respiratory distress syndrome network. N Engl J Med. 2000;342(18):1301-8.

2. Petrucci $N$, De Feo C. Lung protective ventilation strategy for the acute respiratory distress syndrome. Cochrane Database Syst Rev. 2013:2:CD003844.

3. Fernandez-Bustamante A, Wood CL, Tran ZV, Moine P. Intraoperative ventilation: incidence and risk factors for receiving large tidal volumes during general anesthesia. BMC Anesthesiol. 2011;11:22

4. Hess DR, Kondili D, Burns E, Bittner EA, Schmidt UH. A 5-year observational study of lung-protective ventilation in the operating room: a single-center experience. J Crit Care. 2013;28(4):533.e9. 533.e1552.

5. Jaber $\mathrm{S}$, Coisel $Y$, Chanques G, Futier E, Constantin JM, Michelet $P$, et al. A multicentre observational study of intra-operative ventilatory management during general anaesthesia: tidal volumes and relation to body weight. Anaesthesia. 2012;67(9):999-1008.

6. Futier E, Constantin JM, Paugam-Burtz C, Pascal J, Eurin M, Neuschwander A, et al. A trial of intraoperative low-tidal-volume ventilation in abdominal surgery. N Engl J Med. 2013;369(5):428-37

7. Severgnini P, Selmo G, Lanza C, Chiesa A, Frigerio A, Bacuzzi A, et al. Protective mechanical ventilation during general anesthesia for open abdominal surgery improves postoperative pulmonary function. Anesthesiology. 2013;118(6):1307-21.

8. The Prove Network Investigators for the Clinical Trial Network of the European Society of Anaesthesiology. High versus low positive end-expiratory pressure during general anaesthesia for open abdominal surgery (PROVHILO trial): a multicentre randomised controlled trial. Lancet. 2014;384(9942):495-503.

9. Serpa Neto A, Cardoso SO, Manetta JA, Pereira VG, Esposito DC, Pasqualucci Mde $\mathrm{O}$, et al. Association between use of lung-protective ventilation with lower tidal volumes and clinical outcomes among patients without acute respiratory distress syndrome: a meta-analysis. JAMA. 2012;308(16):1651-9.

10. Hemmes SN, Serpa Neto A, Schultz MJ. Intraoperative ventilatory strategies to prevent postoperative pulmonary complications: a meta-analysis. Curr Opin Anaesthesiol. 2013;26(2):126-33.

11. Canet J, Gallart L, Gomar C, Paluzie G, Valles J, Castillo J, et al. Prediction of postoperative pulmonary complications in a population-based surgical cohort. Anesthesiology. 2010;113(6):1338-50.

12. Shander A, Fleisher LA, Barie PS, Bigatello LM, Sladen RN, Watson CB. Clinical and economic burden of postoperative pulmonary complications: patient safety summit on definition, risk-reducing interventions, and preventive strategies. Crit Care Med. 2011;39(9):2163-72.

13. Lellouche F, Dionne S, Simard S, Bussieres J, Dagenais F. High tidal volumes in mechanically ventilated patients increase organ dysfunction after cardiac surgery. Anesthesiology. 2012;116(5):1072-82.

14. Flegal KM, Carroll MD, Ogden CL, Curtin LR. Prevalence and trends in obesity among US adults, 1999-2008. JAMA. 2010;303(3):235-41.
15. Finucane MM, Stevens GA, Cowan MJ, Danaei G, Lin JK, Paciorek CJ, et al. National, regional, and global trends in body-mass index since 1980: systematic analysis of health examination surveys and epidemiological studies with 960 country-years and 9.1 million participants. Lancet. 2011;377(9765):557-67.

16. Nafiu OO, Shanks AM, Hayanga AJ, Tremper KK, Campbell Jr DA. The impact of high body mass index on postoperative complications and resource utilization in minority patients. J Natl Med Assoc. 2011;103(1):9-15.

17. Ferguson MK, Im HK, Watson S, Johnson E, Wigfield CH, Vigneswaran WT. Association of body mass index and outcomes after major lung resection. Eur J Cardiothorac Surg: off J Eur Assoc Cardiothorac Surg. 2014;45(4):e94-9. discussion e99.

18. Liao P, Yegneswaran B, Vairavanathan S, Zilberman P, Chung F. Postoperative complications in patients with obstructive sleep apnea: a retrospective matched cohort study. Can J Anaesth. 2009:56(11):819-28.

19. Kaw R, Pasupuleti V, Walker E, Ramaswamy A, Foldvary-Schafer N. Postoperative complications in patients with obstructive sleep apnea. Chest. 2012;141(2):436-41

20. Ahmad S, Nagle A, McCarthy RJ, Fitzgerald PC, Sullivan JT, Prystowsky J. Postoperative hypoxemia in morbidly obese patients with and without obstructive sleep apnea undergoing laparoscopic bariatric surgery. Anesth Analg. 2008;107(1):138-43.

21. Dreyfuss D, Soler P, Basset G, Saumon G. High inflation pressure pulmonary edema. Respective effects of high airway pressure, high tidal volume, and positive end-expiratory pressure. Am Rev Respir Dis. 1988;137(5):1159-64

22. Dreyfuss D, Saumon G. Ventilator-induced lung injury: lessons from experimental studies. Am J Respir Crit Care Med. 1998;157(1):294-323.

23. Dellinger RP, Levy MM, Rhodes A, Annane D, Gerlach H, Opal SM, et al. Surviving sepsis campaign: international quidelines for management of severe sepsis and septic shock: 2012. Crit Care Med. 2013;41(2):580-637.

24. Villar J. Ventilator or physician-induced lung injury? Minerva Anestesiol. 2005;71(6):255-8.

25. Dreyfuss D, Basset G, Soler P, Saumon G. Intermittent positive-pressure hyperventilation with high inflation pressures produces pulmonary microvascular injury in rats. Am Rev Respir Dis. 1985;132(4):880-4.

26. Tremblay LN, Slutsky AS. Ventilator-induced lung injury: from the bench to the bedside. Intensive Care Med. 2006;32(1):24-33.

27. Muscedere JG, Mullen JB, Gan K, Slutsky AS. Tidal ventilation at low airway pressures can augment lung injury. Am J Respir Crit Care Med. 1994;149(5):1327-34

28. Tremblay L, Valenza F, Ribeiro SP, Li J, Slutsky AS. Injurious ventilatory strategies increase cytokines and c-fos m-RNA expression in an isolated rat lung model. J Clin Invest. 1997;99(5):944-52.

29. Ranieri VM, Suter PM, Tortorella C, De Tullio R, Dayer JM, Brienza A, et al. Effect of mechanical ventilation on inflammatory mediators in patients with acute respiratory distress syndrome: a randomized controlled trial. JAMA. 1999;282(1):54-61.

30. Ranieri VM, Giunta F, Suter PM, Slutsky AS. Mechanical ventilation as a mediator of multisystem organ failure in acute respiratory distress syndrome. JAMA. 2000;284(1):43-4.

31. Haitsma JJ, Uhlig S, Goggel R, Verbrugge SJ, Lachmann U, Lachmann B. Ventilator-induced lung injury leads to loss of alveolar and systemic compartmentalization of tumor necrosis factor-alpha. Intensive Care Med. 2000;26(10):1515-22

32. Haitsma JJ, Uhlig S, Lachmann U, Verbrugge SJ, Poelma DL, Lachmann B. Exogenous surfactant reduces ventilator-induced decompartmentalization of tumor necrosis factor alpha in absence of positive end-expiratory pressure. Intensive Care Med. 2002;28(8):1131-7.

33. Kawano T, Mori S, Cybulsky M, Burger R, Ballin A, Cutz E, et al. Effect of granulocyte depletion in a ventilated surfactant-depleted lung. J Appl Physiol. 1987;62(1):27-33.

34. Ricard JD, Dreyfuss D, Saumon G. Production of inflammatory cytokines in ventilator-induced lung injury: a reappraisal. Am J Respir Crit Care Med. 2001;163(5):1176-80.

35. Sugiura M, McCulloch PR, Wren S, Dawson RH, Froese AB. Ventilator pattern influences neutrophil influx and activation in atelectasis-prone rabbit lung. J Appl Physiol. 1994;77(3):1355-65.

36. Webb HH, Tierney DF. Experimental pulmonary edema due to intermittent positive pressure ventilation with high inflation pressures. Protection by positive end-expiratory pressure. Am Rev Respir Dis. 1974;110(5):556-65. 
37. Costa EL, Musch G, Winkler T, Schroeder T, Harris RS, Jones HA, et al. Mild endotoxemia during mechanical ventilation produces spatially heterogeneous pulmonary neutrophilic inflammation in sheep. Anesthesiology. 2010;112(3):658-69.

38. Treschan TA, Kaisers W, Schaefer MS, Bastin B, Schmalz U, Wania V, et al. Ventilation with low tidal volumes during upper abdominal surgery does not improve postoperative lung function. Br J Anaesth. 2012;109(2):263-71.

39. Determann RM, Royakkers A, Wolthuis EK, Vlaar AP, Choi G, Paulus F, et al. Ventilation with lower tidal volumes as compared with conventional tidal volumes for patients without acute lung injury: a preventive randomized controlled trial. Crit Care. 2010;14(1):R1.

40. Halter JM, Steinberg JM, Gatto LA, DiRocco JD, Pavone LA, Schiller HJ, et al Effect of positive end-expiratory pressure and tidal volume on lung injury induced by alveolar instability. Crit Care. 2007;11(1):R20.

41. Pinheiro De Oliveira R, Hetzel MP, Dos Anjos Silva M, Dallegrave D, Friedman G. Mechanical ventilation with high tidal volume induces inflammation in patients without lung disease. Crit Care. 2010;14(2):R39.

42. Wilson MR, Choudhury S, Goddard ME, O'Dea KP, Nicholson AG, Takata M. High tidal volume upregulates intrapulmonary cytokines in an in vivo mouse model of ventilator-induced lung injury. J Appl Physiol. 2003;95(4):1385-93.

43. Wolthuis EK, Choi G, Dessing MC, Bresser P, Lutter R, Dzoljic M, et al. Mechanical ventilation with lower tidal volumes and positive end-expiratory pressure prevents pulmonary inflammation in patients without preexisting lung injury. Anesthesiology. 2008;108(1):46-54.

44. Belperio JA, Keane MP, Burdick MD, Londhe V, Xue YY, Li K, et al. Critical role for CXCR2 and CXCR2 ligands during the pathogenesis of ventilator-induced lung injury. J Clin Invest. 2002;110(11):1703-16

45. Fernandez-Perez ER, Keegan MT, Brown DR, Hubmayr RD, Gajic O. Intraoperative tidal volume as a risk factor for respiratory failure after pneumonectomy. Anesthesiology. 2006;105(1):14-8.

46. Lee PC, Helsmoortel CM, Cohn SM, Fink MP. Are low tidal volumes safe? Chest. 1990;97(2):430-4

47. Michelet $\mathrm{P}, \mathrm{D}^{\prime}$ Journo XB, Roch A, Doddoli C, Marin V, Papazian L, et al. Protective ventilation influences systemic inflammation after esophagectomy: a randomized controlled study. Anesthesiology. 2006;105(5):911-9.

48. Gajic O, Frutos-Vivar F, Esteban A, Hubmayr RD, Anzueto A. Ventilator settings as a risk factor for acute respiratory distress syndrome in mechanically ventilated patients. Intensive Care Med. 2005;31(7):922-6.

49. Gajic O, Dara SI, Mendez JL, Adesanya AO, Festic E, Caples SM, et al. Ventilator-associated lung injury in patients without acute lung injury at the onset of mechanical ventilation. Crit Care Med. 2004;32(9):1817-24

50. Mascia L, Pasero D, Slutsky AS, Arguis MJ, Berardino M, Grasso S, et al. Effect of a lung protective strategy for organ donors on eligibility and availability of lungs for transplantation: a randomized controlled trial. JAMA. 2010;304(23):2620-7.

51. Lucangelo U, Del Sorbo L, Boffini M, Ranieri VM. Protective ventilation for lung transplantation. Curr Opin Anaesthesiol. 2012;25(2):170-4.

52. Khuri SF, Henderson WG, DePalma RG, Mosca C, Healey NA, Kumbhani DJ, et al. Determinants of long-term survival after major surgery and the adverse effect of postoperative complications. Ann Surg. 2005;242(3):326-41. discussion 341-3.107.

53. Smetana GW. Postoperative pulmonary complications: an update on risk assessment and reduction. Cleve Clin J Med. 2009;76 Suppl 4:S60-5.

54. Lugogo NL, Kraft M, Dixon AE. Does obesity produce a distinct asthma phenotype? J Appl Physiol. 2010;108(3):729-34

55. Sutherland ER, Goleva E, King TS, Lehman E, Stevens AD, Jackson LP, et al. Cluster analysis of obesity and asthma phenotypes. PLoS One. 2012;7(5):e36631.

56. Al-Alwan A, Bates JH, Chapman DG, Kaminsky DA, DeSarno MJ, Irvin CG, et al. The nonallergic asthma of obesity. A matter of distal lung compliance. Am J Respir Crit Care Med. 2014;189(12):1494-502.

57. Garg R, Singh A, Prasad R, Saheer S, Jabeed P, Verma R. A comparative study on the clinical and polysomnographic pattern of obstructive sleep apnea among obese and non-obese subjects. Annals of Thoracic Medicine. 2012;7(1):26-30

58. Kaw R, Michota F, Jaffer A, Ghamande S, Auckley D, Golish J. Unrecognized sleep apnea in the surgical patient: implications for the perioperative setting. Chest. 2006;129(1):198-205.

59. Memtsoudis SG, Besculides MC, Mazumdar M. A rude awakening-the perioperative sleep apnea epidemic. N Engl J Med. 2013;368(25):2352-3.
60. Singh M, Liao P, Kobah S, Wijeysundera DN, Shapiro C, Chung F. Proportion of surgical patients with undiagnosed obstructive sleep apnoea. $\mathrm{Br} J$ Anaesth. 2013;110(4):629-36.

61. Marin JM, Agusti A, Villar I, Forner M, Nieto D, Carrizo SJ, et al. Association between treated and untreated obstructive sleep apnea and risk of hypertension. JAMA. 2012;307(20):2169-76.

62. Lam JC, Mak JC, Ip MS. Obesity, obstructive sleep apnoea and metabolic syndrome. Respirology. 2012;17(2):223-36.

63. Olson AL, Zwillich C. The obesity hypoventilation syndrome. Am J Med. 2005;118(9):948-56.

64. Chau EH, Lam D, Wong J, Mokhlesi B, Chung F. Obesity hypoventilation syndrome: a review of epidemiology, pathophysiology, and perioperative considerations. Anesthesiology. 2012;117(1):188-205.

65. Pepin $J$, Borel JC, Janssens JP. Obesity hypoventilation syndrome: an underdiagnosed and undertreated condition. Am J Respir Crit Care Med. 2012;186(12):1205-7

66. BaHammam A. Acute ventilatory failure complicating obesity hypoventilation: update on a 'critical care syndrome'. Curr Opin Pulm Med. 2010;16(6):543-51.

67. Kheterpal S, Healy D, Aziz MF, Shanks AM, Freundlich RE, Linton F, et al. Incidence, predictors, and outcome of difficult mask ventilation combined with difficult laryngoscopy: a report from the multicenter perioperative outcomes group. Anesthesiology. 2013;119(6):1360-9.

68. Pelosi P, Gregoretti C. Perioperative management of obese patients. Best Pract Res Clin Anaesthesiol. 2010;24(2):211-25.

69. Bucklin BA, Fernandez-Bustamante A. Chapter: obesity and anesthesia. In: Barash PG, Cullen BF, Stoelting RK, Cahalan M, Stock MC, editors. Clinical anesthesia. 7th ed. Philadelphia, PA: Wolters Kluwer/Lippincott Williams \& Wilkins; 2013. p. 1274-93.

70. Pelosi P, Croci M, Ravagnan I, Tredici S, Pedoto A, Lissoni A, et al. The effects of body mass on lung volumes, respiratory mechanics, and gas exchange during general anesthesia. Anesth Analg. 1998;87(3):654-60.

71. Salome CM, King GG, Berend N. Physiology of obesity and effects on lung function. J Appl Physiol. 2010;108(1):206-11.

72. Rubinstein I, Zamel N, DuBarry L, Hoffstein V. Airflow limitation in morbidly obese, nonsmoking men. Ann Intern Med. 1990:112(11):828-32.

73. Bahammam AS, Al-Jawder SE. Managing acute respiratory decompensation in the morbidly obese. Respirology. 2012;17(5):759-71.

74. Steier J, Lunt A, Hart N, Polkey MI, Moxham J. Observational study of the effect of obesity on lung volumes. Thorax. 2014;69(8):752-9.

75. Steier J, Jolley CJ, Seymour J, Roughton M, Polkey MI, Moxham J. Neural respiratory drive in obesity. Thorax. 2009;64(8):719-25.

76. Pankow W, Podszus T, Gutheil T, Penzel T, Peter J, Von Wichert P. Expiratory flow limitation and intrinsic positive end-expiratory pressure in obesity. J Appl Physiol. 1998;85(4):1236-43.

77. Lin CK, Lin CC. Work of breathing and respiratory drive in obesity. Respirology. 2012;17(3):402-11.

78. Chlif M, Keochkerian D, Choquet D, Vaidie A, Ahmaidi S. Effects of obesity on breathing pattern, ventilatory neural drive and mechanics. Respir Physiol Neurobiol. 2009;168(3):198-202.

79. Schug SA, Raymann A. Postoperative pain management of the obese patient. Best Pract Res Clin Anaesthesiol. 2011;25(1):73-81.

80. Cadi P, Guenoun T, Journois D, Chevallier JM, Diehl JL, Safran D. Pressure-controlled ventilation improves oxygenation during laparoscopic obesity surgery compared with volume-controlled ventilation. $\mathrm{Br} J$ Anaesth 2008;100(5):709-16

81. Zoremba M, Kalmus G, Dette F, Kuhn C, Wulf H. Effect of intra-operative pressure support vs pressure controlled ventilation on oxygenation and lung function in moderately obese adults. Anaesthesia. 2010;65(2):124-9.

82. Aldenkortt M, Lysakowski C, Elia N, Brochard L, Tramer MR. Ventilation strategies in obese patients undergoing surgery: a quantitative systematic review and meta-analysis. Br J Anaesth. 2012;109(4):493-502.

83. Hans GA, Pregaldien AA, Kaba A, Sottiaux TM, DeRoover A, Lamy ML, et al. Pressure-controlled ventilation does not improve gas exchange in morbidly obese patients undergoing abdominal surgery. Obes Surg. 2008;18(1):71-6.

84. De Baerdemaeker LE, Van der Herten C, Gillardin JM, Pattyn P, Mortier EP, Szegedi LL. Comparison of volume-controlled and pressure-controlled ventilation during laparoscopic gastric banding in morbidly obese patients. Obes Surg. 2008;18(6):680-5.

85. Dion JM, McKee C, Tobias JD, Sohner P, Herz D, Teich S, et al. Ventilation during laparoscopic-assisted bariatric surgery: volume-controlled, pressure- 
controlled or volume-guaranteed pressure-regulated modes. Int J Clinical Exp. 2014;7(8):2242-7.

86. O'Brien Jr JM, Welsh $\mathrm{CH}$, Fish RH, Ancukiewicz M, Kramer AM. Excess body weight is not independently associated with outcome in mechanically ventilated patients with acute lung injury. Ann Intern Med. 2004;140(5):338-45.

87. Lewandowski K, Lewandowski M. Intensive care in the obese. Best Pract Res Clin Anaesthesiol. 2011;25(1):95-108.

88. Owens RL, Campana LM, Hess L, Eckert DJ, Loring SH, Malhotra A. Sitting and supine esophageal pressures in overweight and obese subjects. Obesity. 2012;20(12):2354-60.

89. Talmor D, Sarge T, Malhotra A, O'Donnell CR, Ritz R, Lisbon A, et al. Mechanical ventilation guided by esophageal pressure in acute lung injury. N Engl J Med. 2008;359(20):2095-104.

90. Pelosi P, Ravagnan I, Giurati G, Panigada M, Bottino N, Tredici S, et al. Positive end-expiratory pressure improves respiratory function in obese but not in normal subjects during anesthesia and paralysis. Anesthesiology. 1999;91(5):1221-31.

91. Talab HF, Zabani IA, Abdelrahman HS, Bukhari WL, Mamoun I, Ashour MA, et al. Intraoperative ventilatory strategies for prevention of pulmonary atelectasis in obese patients undergoing laparoscopic bariatric surgery. Anesth Analg. 2009;109(5):1511-6.

92. Lemyze M, Mallat J, Duhamel A, Pepy F, Gasan G, Barrailler S, et al. Effects of sitting position and applied positive end-expiratory pressure on respiratory mechanics of critically ill obese patients receiving mechanical ventilation*. Crit Care Med. 2013:41(11):2592-9.

93. Wellman TJ, Winkler T, Costa EL, Musch G, Harris RS, Venegas JG, et al. Effect of regional lung inflation on ventilation heterogeneity at different length scales during mechanical ventilation of normal sheep lungs. J Appl Physiol. 2012;113(6):947-57.

94. Meade MO, Cook DJ, Guyatt GH, Slutsky AS, Arabi YM, Cooper DJ, et al. Ventilation strategy using low tidal volumes, recruitment maneuvers, and high positive end-expiratory pressure for acute lung injury and acute respiratory distress syndrome: a randomized controlled trial. JAMA. 2008;299(6):637-45.

95. Barbosa FT, Castro AA, de Sousa-Rodrigues CF. Positive end-expiratory pressure (PEEP) during anaesthesia for prevention of mortality and postoperative pulmonary complications. Cochrane Database Syst Rev. 2014;6:CD007922.

96. Whalen FX, Gajic O, Thompson GB, Kendrick ML, Que FL, Williams BA, et al. The effects of the alveolar recruitment maneuver and positive end-expiratory pressure on arterial oxygenation during laparoscopic bariatric surgery. Anesth Analg. 2006;102(1):298-305

97. Hovaguimian F, Lysakowski C, Elia N, Tramer MR. Effect of intraoperative high inspired oxygen fraction on surgical site infection, postoperative nausea and vomiting, and pulmonary function: systematic review and meta-analysis of randomized controlled trials. Anesthesiology. 2013;119(2):303-16.

98. Rothen HU, Sporre B, Engberg G, Wegenius G, Hogman M, Hedenstierna G. Influence of gas composition on recurrence of atelectasis after a reexpansion maneuver during general anesthesia. Anesthesiology. 1995;82(4):832-42.

99. Campos JH, Hallam EA, Ueda K. Lung isolation in the morbidly obese patient: a comparison of a left-sided double-lumen tracheal tube with the Arndt (R) wire-guided blocker. Br J Anaesth. 2012;109(4):630-5.

100. Katz JA, Laverne RG, Fairley HB, Thomas AN. Pulmonary oxygen exchange during endobronchial anesthesia: effect of tidal volume and PEEP. Anesthesiology. 1982;56(3):164-71.

101. Jeon K, Yoon JW, Suh GY, Kim J, Kim K, Yang M, et al. Risk factors for post-pneumonectomy acute lung injury/acute respiratory distress syndrome in primary lung cancer patients. Anaesth Intensive Care. 2009;37(1):14-9.

102. Maslow AD, Stafford TS, Davignon KR, Ng T. A randomized comparison of different ventilator strategies during thoracotomy for pulmonary resection. J Thorac Cardiovasc Surg. 2013;146(1):38-44.

103. Yang M, Ahn HJ, Kim K, Kim JA, Yi CA, Kim MJ, et al. Does a protective ventilation strategy reduce the risk of pulmonary complications after lung cancer surgery?: a randomized controlled trial. Chest. 2011;139(3):530-7.

104. Licker M, Diaper J, Villiger Y, Spiliopoulos A, Licker V, Robert J, et al. Impact of intraoperative lung-protective interventions in patients undergoing lung cancer surgery. Crit Care. 2009;13(2):R41.

105. Qutub H, El-Tahan MR, Mowafi HA, El Ghoneimy YF, Regal MA, Al Saflan AA. Effect of tidal volume on extravascular lung water content during one-lung ventilation for video-assisted thoracoscopic surgery: a randomised, controlled trial. Eur J Anaesthesiol. 2014;31(9):466-73.
106. Unzueta C, Tusman G, Suarez-Sipmann F, Bohm S, Moral V. Alveolar recruitment improves ventilation during thoracic surgery: a randomized controlled trial. $\mathrm{Br}$ J Anaesth. 2012;108(3):517-24

107. Tusman G, Bohm SH, Sipmann FS, Maisch S. Lung recruitment improves the efficiency of ventilation and gas exchange during one-lung ventilation anesthesia. Anesth Analg. 2004;98(6):1604-9.

108. Park SH, Jeon YT, Hwang JW, Do SH, Kim JH, Park HP. A preemptive alveolar recruitment strategy before one-lung ventilation improves arterial oxygenation in patients undergoing thoracic surgery: a prospective randomised study. Eur J Anaesthesiol. 2011;28(4):298-302.

109. Michelet $P$, Roch A, Brousse D, D'Journo XB, Bregeon F, Lambert D, et al. Effects of PEEP on oxygenation and respiratory mechanics during one-lung ventilation. Br J Anaesth. 2005:95(2):267-73.

110. Gattinoni L, Caironi P, Cressoni M, Chiumello D, Ranieri VM, Quintel M, et al. Lung recruitment in patients with the acute respiratory distress syndrome. N Engl J Med. 2006;354(17):1775-86.

111. Leong LM, Chatterjee S, Gao F. The effect of positive end expiratory pressure on the respiratory profile during one-lung ventilation for thoracotomy. Anaesthesia. 2007;62(1):23-6.

112. Ferrando C, Mugarra A, Gutierrez A, Carbonell JA, Garcia M, Soro M, et al. Setting individualized positive end-expiratory pressure level with a positive end-expiratory pressure decrement trial after a recruitment maneuver improves oxygenation and lung mechanics during one-lung ventilation. Anesth Analg. 2014;118(3):657-65.

113. Cooper L. Postoperative complications after thoracic surgery in the morbidly obese patient. Anesthesiol Res Prac. 2011;2011:865634

114. Joris JL, Sottiaux TM, Chiche JD, Desaive CJ, Lamy ML. Effect of bi-level positive airway pressure (BiPAP) nasal ventilation on the postoperative pulmonary restrictive syndrome in obese patients undergoing gastroplasty. Chest. 1997;111(3):665-70

115. Kalhan R, Mikkelsen M, Dedhiya P, Christie J, Gaughan C, Lanken PN, et al. Underuse of lung protective ventilation: analysis of potential factors to explain physician behavior. Crit Care Med. 2006;34(2):300-6.

116. Blum JM, Maile M, Park PK, Morris M, Jewell E, Dechert R, et al. A Description of Intraoperative Ventilator Management in Patients with Acute Lung Injury and the Use of Lung Protective Ventilation Strategies. Anesthesiology. 2011;115(1):75-82.

117. Anzueto A, Frutos-Vivar F, Esteban A, Bensalami N, Marks D, Raymondos K et al. Influence of body mass index on outcome of the mechanically ventilated patients. Thorax. 2011;66(1):66-73.

118. Gong MN, Bajwa EK, Thompson BT, Christiani DC. Body mass index is associated with the development of acute respiratory distress syndrome. Torax. 2010;65(1):44-50.

119. Memtsoudis SG, Bombardieri AM, Ma Y, Walz JM, Chiu YL, Mazumdar M. Mortality of patients with respiratory insufficiency and adult respiratory distress syndrome after surgery: the obesity paradox. J Intensive Care Med. 2012;27(5):306-11.

120. Morris AE, Stapleton RD, Rubenfeld GD, Hudson LD, Caldwell E, Steinberg KP. The association between body mass index and clinical outcomes in acute lung injury. Chest. 2007;131(2):342-8.

121. O'Brien Jr JM, Phillips GS, Ali NA, Lucarelli M, Marsh CB, Lemeshow S. Body mass index is independently associated with hospital mortality in mechanically ventilated adults with acute lung injury. Crit Care Med. 2006;34(3):738-44

122. Stapleton RD, Dixon AE, Parsons PE, Ware LB, Suratt BT. The association between $\mathrm{BMI}$ and plasma cytokine levels in patients with acute lung injury. Chest. 2010;138(3):568-77.

123. Martino JL, Stapleton RD, Wang M, Day AG, Cahill NE, Dixon AE, et al. Extreme obesity and outcomes in critically ill patients. Chest. 2011;140(5):1198-206.

124. Sakr Y, Madl C, Filipescu D, Moreno R, Groeneveld J, Artigas A, et al. Obesity is associated with increased morbidity but not mortality in critically ill patients. Intensive Care Med. 2008;34(11):1999-2009.

125. Memtsoudis SG, Bombardieri AM, Ma Y, Walz JM, Chiu YL, Mazumdar M. Mortality of Patients With Respiratory Insufficiency and Adult Respiratory Distress Syndrome After Surgery: The Obesity Paradox. J Intensive Care Med. 2012;27(5):306-11.

126. Fernandez-Bustamante A, Repine JE. The obesity ARDS paradox: "A Pre-Conditioning Cloud". J Pulmon Resp Med. 2012;2:e122.

127. Fernandez-Bustamante A, Repine JE. Chronic inflammatory diseases and the Acute Respiratory Distress Syndrome (ARDS). Curr Pharm Des. 2014;20(9):1400-8 
128. Chalhoub V, Yazigi A, Sleilaty G, Haddad F, Noun R, Madi-Jebara S, et al. Effect of vital capacity manoeuvres on arterial oxygenation in morbidly obese patients undergoing open bariatric surgery. Eur J Anaesthesiol. 2007;24(3):283-8.

129. de Souza AP, Buschpigel M, Mathias LA, Malheiros CA, Alves VL. Analysis of the effects of the alveolar recruitment maneuver on blood oxygenation during bariatric surgery. Rev Bras Anestesiol. 2009;59(2):177-86.

130. Futier E, Constantin JM, Pelosi P, Chanques G, Massone A, Petit A, et al. Noninvasive ventilation and alveolar recruitment maneuver improve respiratory function during and after intubation of morbidly obese patients: a randomized controlled study. Anesthesiology. 2011;114(6):1354-63.

131. Reinius $H$, Jonsson L, Gustafsson S, Sundbom M, Duvernoy O, Pelosi P, et al. Prevention of atelectasis in morbidly obese patients during general anesthesia and paralysis: a computerized tomography study. Anesthesiology. 2009;111(5):979-87.

\section{Submit your next manuscript to BioMed Central and take full advantage of:}

- Convenient online submission

- Thorough peer review

- No space constraints or color figure charges

- Immediate publication on acceptance

- Inclusion in PubMed, CAS, Scopus and Google Scholar

- Research which is freely available for redistribution 